\title{
Quarry plans in the management of water resources: case study of the River Serio
}

\author{
G. Ravazzani ${ }^{1}$, M. Mancini ${ }^{1} \& \mathrm{~S}$. Meucci $^{2}$ \\ ${ }^{I}$ DIIAR-CIMI, Milan Polytechnic, Italy \\ ${ }^{2}$ MMI s.r.l., Milan, Italy
}

\begin{abstract}
This work investigates the possibility of rehabilitating and using volumes made available by the creation of quarries of inert materials in watercourse flood plains for the regulation of floods and for the maintenance of supplies in times of water scarcity. Such activities offer technical and economic synergies between the need for production of inert materials and the benefits that such excavations, given appropriate expedients, can provide both in reducing the flood risk and in mitigating shortages. The work in question fully complies with the terms of the Catchment Area and Water Conservation Plan, demonstrating moreover that the required rehabilitation operations are of low impact and are fully sustainable. The case study concerns the last stretch of the River Serio in the province of Cremona.

Keywords: quarries, water scarcity, water supplies, sustainable management, conflicts, irrigation, flow duration curve.
\end{abstract}

\section{Introduction}

In the Lombardy region, in Italy, the water supplies are maintained by heterogeneous resources, such as natural lakes, artificial reservoirs mostly located in mountains, groundwater and natural springs widespread in the southern part of the region. Water resources have been traditionally utilized for human consumptions, hydropower and thermoelectric production and, above all, agricultural irrigation. In the most recent years an increased environmental sensibility asked for the respect of the minimum flows for aquatic life conservation. Despite the natural abundance of water in Lombardy, shortage of water in recent years and the increase of consumptions, have exasperated the conflict between the users. In the last emergencies for water scarcity, irrigation 
deficit has been calculated as $20 \%\left(1495\right.$ million $\left.\mathrm{m}^{3}\right)$ with an equivalent economic damage of 230 million euro in Lombardy. In this situation new management rules and water resources are required taking into account the needs of all the stakeholders.

An interesting water resource which can help in complying with the requests in shortage period is the water stored into the quarries of inert material. A recent regional census has counted more than 700 quarry lakes in Lombardy (Regione Lombardia [6]), most located in watercourse flood plain where agriculture is the main human activity. These manmade reservoirs cover a surface of about $100 \mathrm{~km}^{2}$ with an available water volume estimated in the range $350-700$ million $\mathrm{m}^{3}$. In front of these numbers, the volume of water that can be extracted from the quarries is comparable to the volume of traditional water resources, which are subject to an intensive exploitation. Quarry reservoirs may, then, become a strategic means for the mitigation of water scarcity.

The work presented in this paper investigates the possibility and the efficiency of using the water of the quarry lakes for the reduction of negative effects of water scarcity on environment and economy. In addition an evaluation of the positive effects of the quarries on the regulation of flood and consequently on the reduction of the hydraulic risk is made (not presented in this paper; for further details refer to Provincia di Cremona [5]).

\section{The study area}

The study area involves three quarries located in the north of the city of Crema, in proximity of the river Serio (fig. 1). The quarries today cover a surface of $314850 \mathrm{~m}^{2}$ but in the near future an expansion of $258600 \mathrm{~m}^{2}$ is planned (tab. 1).

The river Serio watershed covers an area of about $940 \mathrm{~km}^{2}\left(711 \mathrm{~km}^{2}\right.$ at the section of the quarries). The river takes origin in the Barbellino Lakes at an elevation of $2100 \mathrm{~m}$ a.s.1. joining the river Adda after a distance of $124 \mathrm{~km}$. The upstream part of the basin is characterized by high mountains with steep slopes. Downstream the section of Alzano Lombardo, the river flows down into the plain and the average slope decreases. When the river goes into the province of Cremona, in proximity of Mozzanica, the flow is regulated by the contribution of natural springs ("fontanili") which are widespread in this area of the basin: Roggia Vidolasca, Roggia Babbiona, Roggia Menasciutto, Roggia Molinara, Roggia Cataletto, Canale Vacchelli, Roggia Rino Fontana, Roggia Cresmiero, Bocchello Oche, Fosso Fuga, Bocchello Ripalta, Roggia Acqua Rossa, Roggia Comuna, Roggia Malcontenta, Roggia Archetta, Roggia Borromea (Provincia di Cremona [4]).

\subsection{Available data}

Cartographic and time series data available for the study include: digital elevation model, lithologic atlas, land use map, long series discharge measurements at Ponte Cene station, discharge data for the station of Mozzanica and Montodine only for the most recent flood event, rainfall measurements, cross section survey of river Serio. 
Table 1: Characteristics of the quarries.

\begin{tabular}{|c|c|c|c|c|}
\hline & \multicolumn{2}{|c|}{ Actual state } & \multicolumn{2}{c|}{ Planned expansion } \\
\hline Quarry code & Surface $\left[\mathrm{m}^{2}\right]$ & Depth $[\mathrm{m}]$ & Surface $\left[\mathrm{m}^{2}\right]$ & Depth $[\mathrm{m}]$ \\
\hline ATE g2 & 51400 & 16 & 0 & - \\
\hline ATE g3 & 163250 & 15 & 160000 & 15 \\
\hline ATE g4 & 100200 & 15 & 98600 & 15 \\
\hline total & 314850 & - & 258600 & - \\
\hline
\end{tabular}

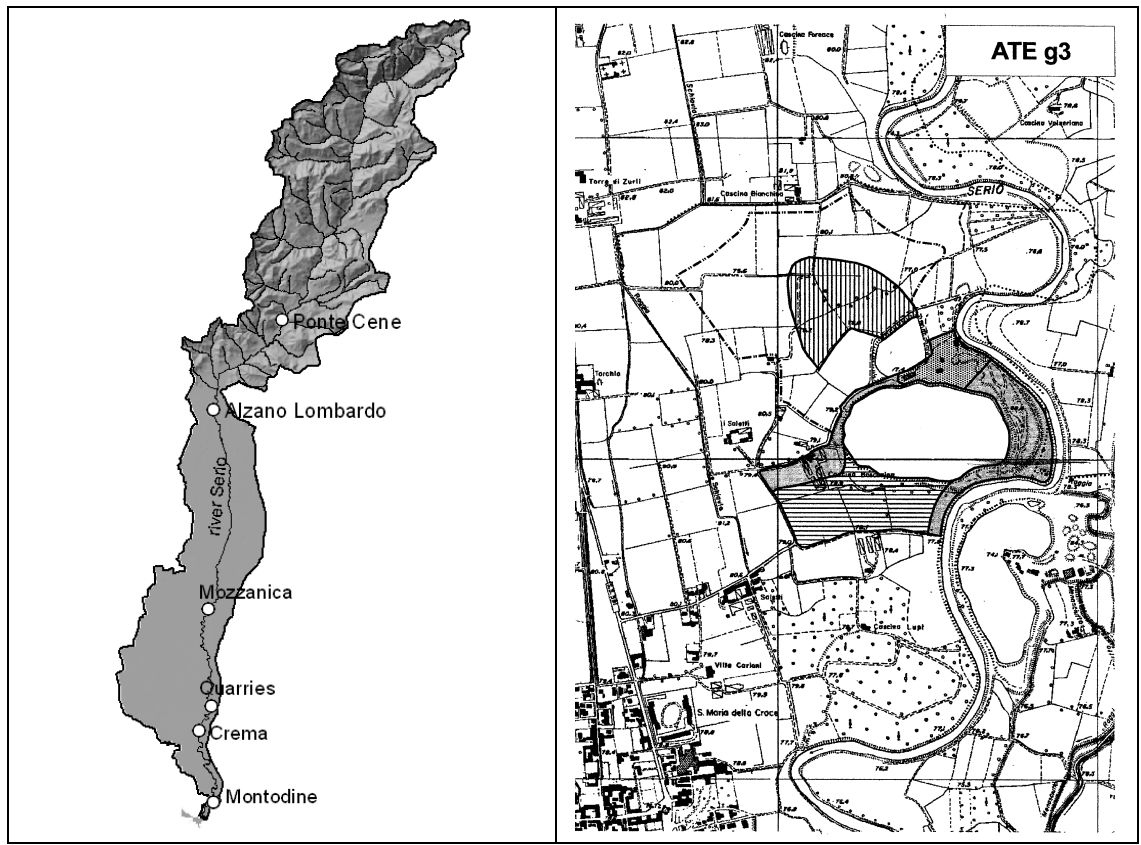

Figure 1: $\quad$ River Serio hydrographic basin (left) and a detail of ATE-g3 quarry and planned expansion (right).

\section{Drought hydrology}

The analysis of the available water in the river is based on the flow duration curve. Discharge measurements are not available for the section where quarries are located; in this case it is possible to use regional methods for the evaluation of an approximated natural flow duration curve (Bartolini et al [1]).

According to the adopted method, the flow duration curve can be written as:

$$
D(q)=365\left[1-F_{q}(q)\right]
$$

where $D$ denotes duration in days, $q$ the discharge in $\mathrm{m}^{3} / \mathrm{s}$ and $F_{q}$ the cumulative frequency. 
The adopted probability distribution function (PDF) is the lognormal distribution:

$$
f(y)=\frac{1}{\sigma_{y} \sqrt{2 \pi}} \exp \left\{-\frac{1}{2}\left[\frac{y-\mu_{y}}{\sigma_{y}}\right]^{2}\right\}
$$

where $y=\ln (q)$ denotes the reduced variable and:

$$
\begin{gathered}
\sigma_{y}^{2}=\ln \left[\left(\frac{\sigma_{q}}{\mu_{q}}\right)^{2}+1\right] \\
\mu_{y}=\ln \left(\mu_{q}\right)-0.5 \sigma_{y}^{2} \\
\mu_{q}=a_{1} S^{b_{1}} H^{c_{1}} \\
\sigma_{q}=a_{2} S^{b_{2}} H^{c_{2}}
\end{gathered}
$$

where $S$ denotes surface of the basin in $\mathrm{km}^{2}$ and $H$ denotes average annual rainfall depth in meter.

Evaluation of model parameters, $a_{1}, b_{1}, c_{1}, a_{2}, b_{2}, c_{2}$, (tab. 2), has been conducted by a trial and error approach matching flow duration curve of the Ponte Cene section where discharge data are available (\$2.1). It is possible, then, to evaluate flow duration curve for the ungauged river sections. If the section drains a basin in which anthropic effects are important (e.g. withdrawals for irrigation or intakes from wastewater treatment plants) the flow duration curve is modified by adding or subtracting the average annual artificial contribution. The natural and anthropic flow duration curves for the section of quarries is shown in fig. 2. In that figure the minimum flow necessary for life (critical flow), evaluated as the $10 \%$ of the annual average natural discharge, according to the Regional Water Plan for Water Management, is reported. Its value is then fixed to $3.06 \mathrm{~m}^{3} / \mathrm{s}$. From the comparison of anthropic flow duration curve and minimum flow it is possible to note that river discharge is lower than the critical for about 24 days in a year. The deficit volume, highlighted in grey in fig. 2, sums up to $3700000 \mathrm{~m}^{3}$.

Table 2: Parameters for evaluation of flow duration curve in ungauged section.

\begin{tabular}{|c|c|c|c|c|c|}
\hline$a_{1}$ & $a_{2}$ & $a_{3}$ & $b_{1}$ & $b_{2}$ & $b_{3}$ \\
\hline 0.0216 & 0.99 & 1.43 & 0.023 & 0.924 & 1.148 \\
\hline
\end{tabular}




\section{Quarry management during water scarcity}

In the river reach downstream the quarries, the Regional Water Plan for Water Management reports three withdrawals for agricultural use: Roggia Borromea $\left(1.4 \mathrm{~m}^{3} / \mathrm{s}\right)$, roggia Malcontenta $\left(0.44 \mathrm{~m}^{3} / \mathrm{s}\right)$ and a whole of little irrigation channels summing up to $0.42 \mathrm{~m}^{3} / \mathrm{s}$, with a total of $2.26 \mathrm{~m}^{3} / \mathrm{s}$. The sum of the aforementioned withdrawals and the minimum critical flow gives the river discharge that satisfies environmental quality and agricultural needs.

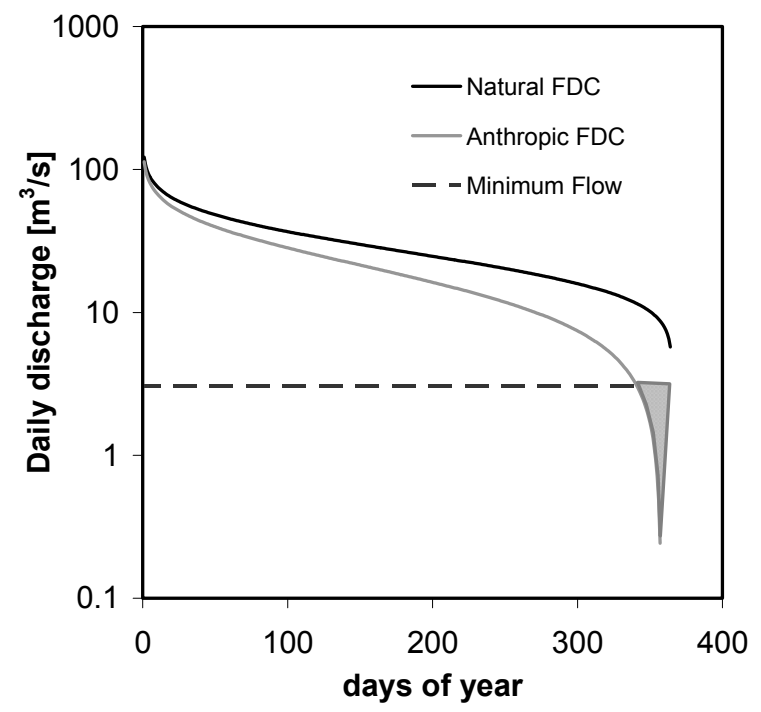

Figure 2: Evaluation of the flow duration curve (FDC) of the river Serio for ungauged section where quarries are located: natural FDC in black line, anthropic FDC in grey line and minimum critical flow in dashed black line. Grey area represents the deficit volume $\left(3700000 \mathrm{~m}^{3}\right)$.

We suppose three scenarios for the employment of the volume of water contained in the quarries. The available water is calculated considering the future expansion plan (total surface covered is $573450 \mathrm{~m}^{2}$ ). The three quarries are considered as an unique storage. The water inflow to the quarries coming from groundwater is considered negligible.

The first scenario gives priority to the environment conservation, guaranteeing the minimum flow in the river for natural life during all the year. This hypothesis is satisfied by a volume of water of $3700000 \mathrm{~m}^{3}$ (fig. 2) that corresponds to a drawdown of the water surface level in the quarries of about $6.5 \mathrm{~m}$.

The second scenario is intended to satisfy the irrigation needs adding to the river Serio a volume of water necessary to guarantee the three downstream 
withdrawals on the occurrence of water scarcity. With a drawdown of the water surface level in the quarries of $2 \mathrm{~m}, 4 \mathrm{~m}$ or $5.5 \mathrm{~m}$, the extracted volume can maintain irrigation for, in order, 6,12 and 16 days.

The third scenario is the ideal situation in which both environment conservation and agricultural needs are satisfied. In this hypothesis the discharge which must be preserved in the river Serio is $5.32 \mathrm{~m}^{3} / \mathrm{s}$, sum of minimum critical flow and the downstream water withdrawals. Unfortunately, the necessary volume $\left(10000000 \mathrm{~m}^{3}\right)$ is greater than total water stored in the three quarries. It is , then impossible to put in action the ideal scenario.

\section{Draining time and interaction with the river}

It is interesting to evaluate the time needed for the draining of the quarries. The three quarries are considered as an unique system characterized by an initial water surface at $75 \mathrm{~m}$ a.s.l. The aquifer is considered isotropic with an hydraulic conductivity $K$ of $3 \cdot 10^{-5} \mathrm{~m} / \mathrm{s}$ as reported in the Regional Water Plan for Water Management. The minimum water level in the lakes is fixed to $69.5 \mathrm{~m}$ a.s.1., which corresponds to a drawdown of $5.5 \mathrm{~m}$. The dynamic of the water level and, consequently the draining of the storage, is modelled with mass balance equation:

$$
\frac{\Delta W}{\Delta t}=Q_{i}-Q_{o}
$$

where $Q_{o}$ is the extracted discharge and $Q_{i}$ is the inflow discharge coming from the aquifer given by (Citrini and Noseda [2]):

$$
Q_{i}=\left(h_{2}^{2}-H_{q}^{2}\right) \frac{K P}{2 L}
$$

where $h_{2}(\mathrm{~m})$ is the undisturbed piezometric head at a distance $L(\mathrm{~m})$ from the quarry, $H_{q}(\mathrm{~m})$ is the level in the quarry, $P(\mathrm{~m})$ is the perimeter of the quarry and $K$ is the hydraulic conductivity $(\mathrm{m} / \mathrm{s})$. The length of influence, $L$, is evaluated with the empiric equation:

$$
L=573(h-H) \sqrt{K h}
$$

valid for the steady state (tab. 3).

Table 3: Length of influence, $\mathrm{L}$, evaluated by means of (5) considering two different values of hydraulic conductivity.

\begin{tabular}{|c|c|c|c|}
\hline $\mathrm{h}-\mathrm{H}(\mathrm{m})$ & $\mathrm{K}(\mathrm{m} / \mathrm{s})$ & $\mathrm{h}(\mathrm{m})$ & $\mathrm{L}(\mathrm{m})$ \\
\hline 5.5 & $3 \cdot 10^{-4}$ & 75 & 472 \\
\hline 5.5 & $3 \cdot 10^{-5}$ & 75 & 149 \\
\hline
\end{tabular}

As the evaluation of hydraulic conductivity is, as well known, subject to great uncertainty, in this study three values are considered: the aforementioned $3 \cdot 10^{-5}$ $\mathrm{m} / \mathrm{s}, 3 \cdot 10^{-9}$ and $3 \cdot 10^{-4} \mathrm{~m} / \mathrm{s}$. The draining time and the extracted volumes are evaluated considering, in the first case, $Q_{o}=2.26 \mathrm{~m}^{3} / \mathrm{s}$ and, in the second case, $Q_{o}=3.06 \mathrm{~m}^{3} / \mathrm{s}$ (§4). Results are reported in the fig. 3 . 
The draining times, reported in tab. 4, can be evaluated as the intersection of drawdown line and the horizontal dashed line which represents the maximum drawdown.
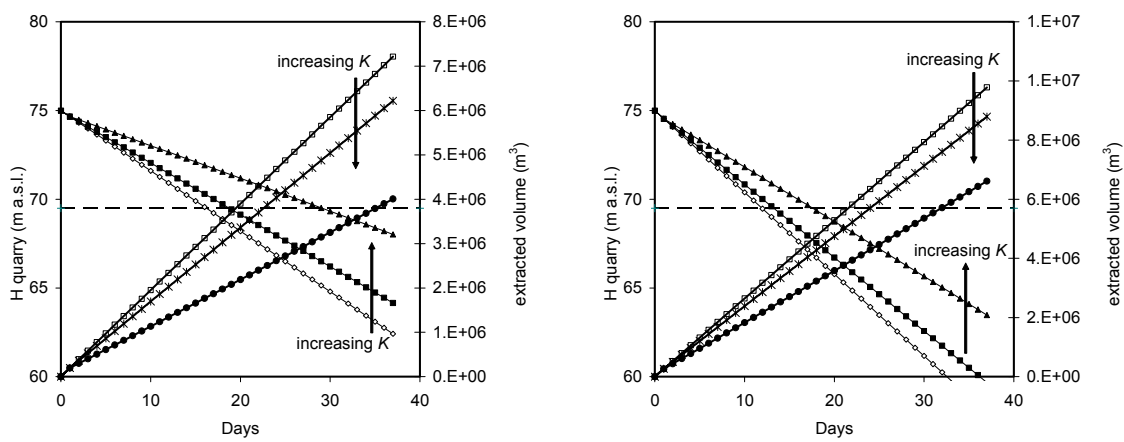

Figure 3: Evaluation of the drawdowns (decreasing lines) and extracted volume (increasing lines) for a pumping discharge of $2.26 \mathrm{~m}^{3} / \mathrm{s}$ (left) and 3.06 $\mathrm{m}^{3} / \mathrm{s}$ (right). Values of hydraulic conductivity are $3 \cdot 10^{-4} \mathrm{~m} / \mathrm{s}, 3 \cdot 10^{-5}$ and $3 \cdot 10^{-9} \mathrm{~m} / \mathrm{s}$. The dashed horizontal line represents the maximum drawdown.

Table 4: Draining times as a function of the hydraulic conductivity, K, and pumping water, $\mathrm{Q}$.

\begin{tabular}{|c|c|c|}
\hline $\mathrm{K}(\mathrm{m} / \mathrm{s})$ & $\mathrm{Q}(\mathrm{m} 3 / \mathrm{s})$ & Draining time (days) \\
\hline $3 \cdot 10^{-9}$ & 2.26 & 19 \\
\hline $3 \cdot 10^{-5}$ & 2.26 & 22 \\
\hline $3 \cdot 10^{-4}$ & 2.26 & 29 \\
\hline $3 \cdot 10^{-9}$ & 3.06 & 12 \\
\hline $3 \cdot 10^{-4}$ & 3.06 & 14 \\
\hline $3 \cdot 10^{-5}$ & 3.06 & 18 \\
\hline
\end{tabular}

From eqn. (4) it is possible to calculate the piezometric head distribution when the drawdown has reached its maximum. For a given pumping discharge $Q$, and a given hydraulic conductivity $K$, the water table $h_{2}$ is calculated as a function of the distance from the quarry $H$ according to eqn. (6). It is so possible to analyse interaction of quarry with river Serio and aquifer.

$$
h_{2}=\left(H^{2}+\frac{2 Q L}{K P}\right)^{0.5}
$$

The results are shown in fig. 4 in which a representative section involving ATEg3 and ATE-g4 quarries and a cross section of the river Serio is reported. Analysis of piezometric head shows a possible interaction with the river Serio, but water exchange is negligible due to low hydraulic conductivity of river bed material. 


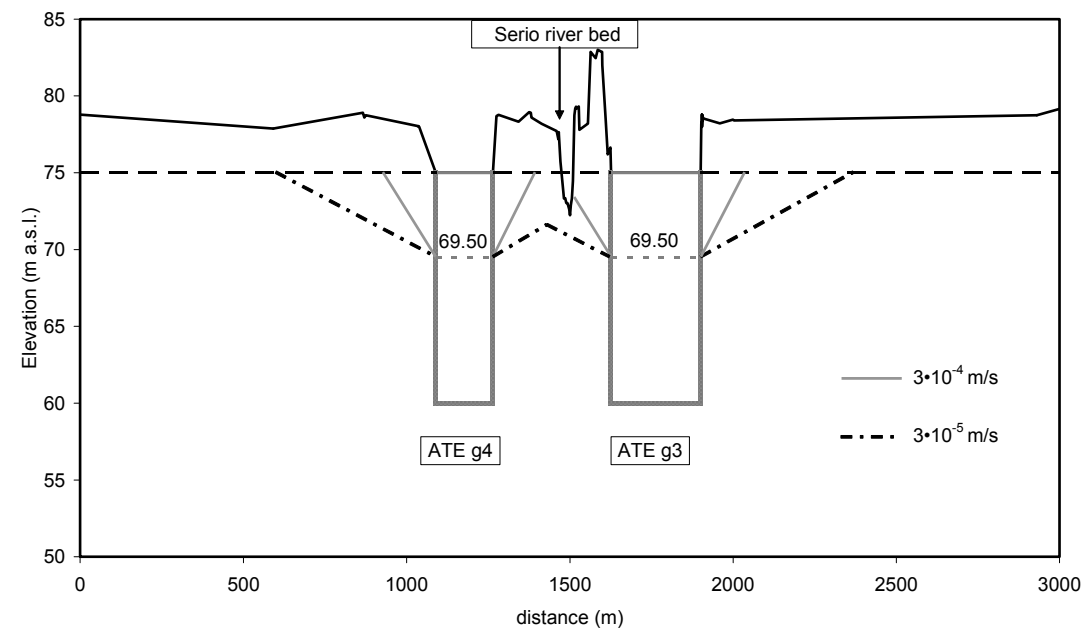

Figure 4: Representative cross section involving ATE-g3 and ATE-g4 quarries and Serio river bed. Water table for a drawdown of $5.5 \mathrm{~m}$ and two different values for hydraulic conductivity are displayed.

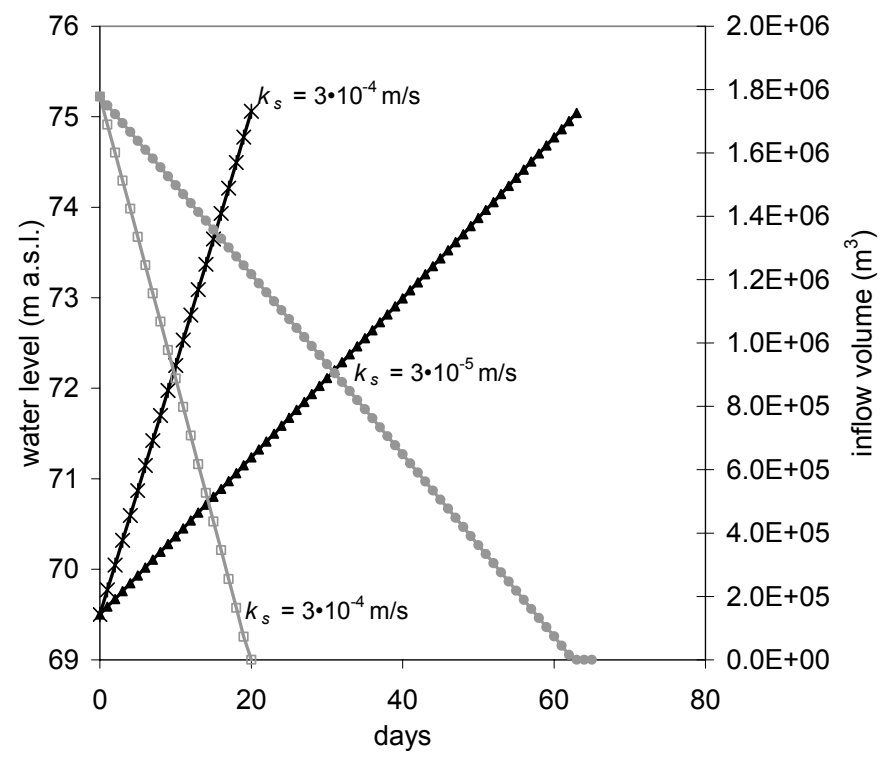

Figure 5: Water level in the quarry ATE-g3 during refilling (black lines) and inflow volume (grey lines). Value of hydraulic conductivity is displayed on the chart. 


\section{Refilling time}

In a similar way to the evaluation of draining time, it is possible to calculate the refilling time, the time necessary to restore undisturbed water table level. In this calculation we made the hypothesis that natural and anthropic events (rainfall or irrigation) are negligible.

In fig. 5 we show the details for ATE-g3 quarry, as the others have similar behaviour. The necessary time for total refilling of the lake varies from 20 days for an aquifer hydraulic conductivity of $3 \cdot 10^{-4} \mathrm{~m} / \mathrm{s}$ and 63 days for hydraulic conductivity of $3 \cdot 10^{-5} \mathrm{~m} / \mathrm{s}$.

\section{Conclusions}

In the present study we investigated the possibility of rehabilitating and using volumes made available by the creation of quarries of inert materials in watercourse flood plains for maintenance of supplies in times of water scarcity. The results show the great importance quarries may have in environment conservation and agricultural activities. With a drawdown of $5.5 \mathrm{~m}$, in fact, it is possible to maintain in the river Serio the discharge necessary for the downstream water withdrawals for a 16 days period. Alternatively, by means of the same drawdown, it is possible to maintain the minimum flow in the river for natural life for a 12 days period. However, the available water volume is not enough to satisfy both environment conservation and agricultural needs.

The piezometric head depression induced by pumping may interact with the river Serio level itself, but the conductivity of river bed is very low so that exchange with the water table can be considered negligible.

\section{Acknowledgments}

This work was supported by Settore Ambiente della Provincia di Cremona. We thank in particular: Mara Pesaro, Ferrari, Chiara Gerevini, Livio Mazzolini (Provincia di Cremona); Paolo Lassini (Regione Lombardia); Stefano Loffi (Consorzio Irrigazioni Cremonesi); Tabellini, Pancaldi (Autorità di Bacino del fiume Po); Roberto Serra, Andrea Cassani (Agenzia Regionale per la Protezione dell'Ambiente della Regione Lombardia); Marengoni (Consorzio di Bonifica della Media Pianura Bergamasca); Daniele Silvani, Arpini (Comune di Crema); La Veglia, Scarpini, Aielli, Barracca (Agenzia Interregionale per il Fiume Po).

\section{References}

[1] Bartolini, P., Bochicchio, M., Giunciuglio, R., Morten, E., Il progetto idro: e-government delle risorse idriche in Liguria, in italian. www.ordineingegneri.genova.it/documenti/Rapallo\%202004/Presentazion i/Bartolini\%20Bochicchio.pdf. 
276 Sustainable Irrigation Management, Technologies and Policies

[2] Citrini, D., Noseda, g., Idraulica, Casa Editrice Ambrosiana, Milano, 1987.

[3] Franzetti, S., Manuale dell'ingegnere, nuovo Colombo, II-H, Chap 3.1 "Acque sotterranee", Hoepli, 1985.

[4] Provincia di Cremona, Piano di Emergenza Provinciale per il Rischio Idraulico dei fiumi Adda, Serio e Oglio.

[5] Provincia di Cremona, Uso delle cave di inerti per l'analisi della laminazione di piena del fiume Serio tra Mozzanica e Crema ed eventuale utilizzo a sostegno delle portate di minimo vitale, 2006.

[6] Regione Lombardia, URBIM, Studio Ambientale, I laghi di cava per l'irrigazione Agricola, in italian, 2005. 